\title{
Endotoxin-Induced Hypoxic-Ischemic Tolerance Is Mediated by Up-regulation of Corticosterone in Neonatal Rat
}

\author{
TOMOAKI IKEDA, LI YANG, TSUYOMU IKENOUE, CARINA MALLARD, AND HENRIK HAGBERG
}

Department of Obstetrics and Gynecology [T.Iked., L.Y., T.Iken.], Miyazaki Medical College, University of Miyazaki, Miyazaki, $889-1692$ Japan; Department of Physiology [C.M.], Department of Obstetrics and Gynecology [H.H.], Institute for the Health of Women and Children, Goteborg University, SE 40530 Göteborg, Sweden

\begin{abstract}
Previous studies suggest that the endotoxin lipopolysaccharide (LPS) may have dual effects on brain damage induced by hypoxia-ischemia (HI) in 7-d-old rats, depending on the exposure paradigm. Although a 4-h interval between LPS administration and $\mathrm{HI}$ results in sensitization to HI brain injury, tolerance is observed when LPS is administered $24 \mathrm{~h}$ before HI. Our hypothesis is that endogenous corticosteroids are important in acquiring tolerance to HI. Neonatal rats received a single injection of LPS $(1.0 \mathrm{mg} / \mathrm{kg})$ either $4 \mathrm{~h}$ or $24 \mathrm{~h}$ before HI, or two LPS injections ( $4 \mathrm{~h}$ and $24 \mathrm{~h}$ ) before HI. Increased brain injury was seen in animals subjected to a single LPS injection made $4 \mathrm{~h}$ before HI. In contrast, both the single 24-h exposure and the double injections of LPS resulted in tolerance to HI brain damage. To study the effects of corticosteroids on $\mathrm{HI}$ tolerance, RU486, a glucocorticoid receptor blocker, was subcutaneously injected at the same time as LPS $(1.0 \mathrm{mg} / \mathrm{kg}), 24 \mathrm{~h}$ before HI stress. RU486-LPS treatment counteracted the LPS-induced tolerance effect, and aggravated the HI-induced brain injury compared with the vehicle-LPS-treated group. RU486 did not aggravate the $\mathrm{HI}$-induced brain injury produced $24 \mathrm{~h}$ later in saline-injected animals. LPS $(1.0 \mathrm{mg} / \mathrm{kg})$ injected into 6-d-old rats transiently upregulated serum corticosterone levels (119.6, 57.9, 56.8, and 28.3 $\mathrm{ng} / \mathrm{mL}$ at $6,12,24$, and $48 \mathrm{~h}$ after the LPS injection, respectively). We conclude that endotoxin-induced up-regulation of endogenous corticosterone appears to be critical for acquiring endotoxin-induced HI tolerance. (Pediatr Res 59: 56-60, 2006)
\end{abstract}

$\mathrm{I}^{\mathrm{n}}$ ntrauterine infection has dual impacts on perinatal mortality and morbidity. It is widely known that white matter injury, intraventricular hemorrhage, cerebral palsy, and chronic lung disease are associated with chorioamnionitis and preterm delivery $(1,2)$. However, survival after preterm delivery at less than 34 wk of gestation is higher in infants with histologic evidence of chorioamnionitis compared with those without (3). Chorioamnionitis also decreases the incidence of respiratory distress syndrome, which correlates with elevated fetal cytokine levels in umbilical cord blood (4). This uncertainty in the clinical consequences of the infection or inflammation may be partly explained by the variability in time between the onset of infection and inflammation and the delivery. Delivery is one of the most stressful of perinatal events. Recent findings

Received March 8, 2005; accepted June 21, 2005.

Correspondence: Tomoaki Ikeda, M.D., Department of Obstetrics and Gynecology, Miyazaki Medical College, 5200 Kihara, Kiyotake-Cho, Miyazaki 889-1692, Japan; e-mail: tikeda44@hotmail.com

DOI: 10.1203/01.pdr.0000191140.87314.ce by Eklind et al. (5) are consistent with this view. When the endotoxin LPS was administered to 7-d-old rats at either 4-6 $\mathrm{h}$ or $72 \mathrm{~h}$ before HI, cerebral injury was more severe. However, when LPS was injected $24 \mathrm{~h}$ before HI, cerebral injury was reduced; this has also been observed in adult rats following cerebral ischemia (6). In the latter phenomenon, known as HI tolerance or preconditioning $(7,8)$, a preceding sublethal stress, such as hypoxia (7) or hyperthermia (9), in immature brains, ameliorates the subsequent HI-induced brain injury. Understanding the mechanisms for endotoxin-induced tolerance may help prevent neurologic adverse outcomes after intrauterine infection and inflammation.

LPS-induced corticosteroids are believed to protect the nervous systems of adult rats against bacterial infections by activating glucocorticoid receptors. Mifepristone (RU486) increases the inflammatory reaction in the brain following intracerebral injection of LPS (10). We have also shown that dexamethasone treatment prevents histologic and behavioral impairment following the combination of LPS treatment and $\mathrm{HI}$ in neonatal rats (11).

We examined the cerebral effects of the interaction between LPS and HI in neonatal animals in this study, with the hypothesis that endogenous corticosteroids are important in the acquisition of endotoxin-induced HI tolerance in the brain.

\section{MATERIALS AND METHODS}

Animals. The Animal Research Committee of Miyazaki Medical College approved this study. Pregnant Wistar rats were purchased from a regional vendor (Japan Charles River, Atsugi, Japan). We selected 195 pups $6 \mathrm{~d}$ after birth whose weights were within the range determined by our laboratory to be suitable for this experimental protocol.

Model for inducing $\mathbf{H I}$. HI stress was produced in 7-d-old rats using the following modification of Levine's method $(12,13)$. Pups were anesthetized with ether, and the left carotid artery was sectioned between two 4-0 silk ligatures. The pups were allowed to recover for $1-2 \mathrm{~h}$ and then exposed to 60 min or 120 min of hypoxia in a plastic container perfused with a mixture of humidified $8 \%$ oxygen in nitrogen. We adjusted the time duration of hypoxic stress for appropriately discriminative observation. The temperature inside the container was $33^{\circ} \mathrm{C}$, the temperature to which rat pups are exposed when huddling with their mother (14).

Experimental protocols for LPS and HI insult. The first series of experiments used different LPS challenge protocols before HI stress (Table 1). LPS

Abbreviations: HI, hypoxia-ischemia or hypoxic-ischemic; LPS lipopolysaccharide 
Table 1. Experimental protocol

\begin{tabular}{llcccc}
\hline $\begin{array}{c}\text { Experimental no.) } \\
\text { study groups }\end{array}$ & $\begin{array}{c}\text { Pre-24 h s.c. } \\
\text { injection }\end{array}$ & $\begin{array}{c}\text { Pre-24 h i.p. } \\
\text { injection }\end{array}$ & $\begin{array}{c}\text { Pre-4 h i.p. } \\
\text { injection }\end{array}$ & $\begin{array}{c}\text { Duration of } \\
\text { HI (min) }\end{array}$ & $\begin{array}{c}\text { No. } \\
\text { animals }\end{array}$ \\
\hline (1) LPS4h & N & Saline & LPS & 60 & 14 \\
(1) Saline4h & N & Saline & Saline & 60 & 14 \\
(2) LPS24h & N & LPS & Saline & 120 & 14 \\
(2) Saline24h & N & Saline & Saline & 120 & 14 \\
(3) LPS24h + LPS4h & N & LPS & LPS & 120 & 14 \\
(3) Saline24h + Saline4h & N & Saline & Saline & 120 & 14 \\
(4) Saline24h-RU486 & RU-486 & Saline & Saline & 120 & 14 \\
(4) Saline24h-vehicle & DMSO & Saline & Saline & 120 & 14 \\
(5) LPS24h-RU486 & RU486 & LPS & Saline & 120 & 14 \\
(5) LPS24h-vehicle & DMSO & LPS & Saline & 120 & 14 \\
(6) LPS24h & N & LPS & N & N & 13 \\
(6) Saline24h (serum CORT) & N & Saline & N & N & 13 \\
\hline
\end{tabular}

Pre, before HI stress; s.c., subcutaneous; i.p, intraperitoneal; N, not performed; CORT, corticosterone.

$(1.0 \mathrm{mg} / \mathrm{kg}$ ) from the same lot number was used throughout (Escherichia coli, serotype 026:B6, Sigma Chemical Co., St. Louis, MO). LPS (0.1 mL per $10 \mathrm{~g}$ body weight) or vehicle (normal saline, $0.1 \mathrm{~mL}$ per $10 \mathrm{~g}$ body weight) was injected intraperitoneally at either $4 \mathrm{~h}$ or $24 \mathrm{~h}$ before HI. In other pups, we administrated the same dose of LPS at both 4 and $24 \mathrm{~h}$ before HI. Control rats had normal saline injections rather than no injections, as it has been shown that saline injections can increase plasma corticosterone in neonatal rats (15).

The second series of experiments examined blocking with RU486, a glucocorticoid receptor blocker. RU486 (BIOMOL Research Laboratories Inc. Plymouth Meeting, PA) (60 $\mu \mathrm{g} / \mathrm{kg}$ dissolved in $10 \%$ DMSO) was injected subcutaneously $24 \mathrm{~h}$ before HI, on postnatal day (PND) 6. This dosage significantly reversed the neuroprotective effect of dexamethasone in the study by Tuor $e$ t al. (16). RU486-treated rats were compared with vehicle (DMSO)-treated rats, in groups that received saline-saline injections, or LPS-saline injections, at $4 \mathrm{~h}$ and $24 \mathrm{~h}$ before $\mathrm{HI}$.

Serum corticosterone level after LPS administration. Serum corticosterone levels were measured in 6-d-old rats. Just before, and at 6, 12, 24, and $48 \mathrm{~h}$ after intraperitoneal injections with LPS $(1.0 \mathrm{mg} / \mathrm{kg})$, a blood sample was withdrawn via cardiac puncture as each animal was killed. LPS injections were made at $0900 \mathrm{~h}$. Serum was separated from each sample and its corticosterone level was measured using the ${ }^{125}$ I RIA kit (Coat-A-Count Rat Corticosterone kit, Diagnostic Products Corporation, Los Angeles, CA). The measurable range was $20-2000 \mathrm{ng} / \mathrm{mL}$. Saline-treated animals were also measured at the times corresponding to those for the LPS-treated group.

Histologic analysis. One week after the $\mathrm{HI}$ insult, animals were anesthetized and killed, and the brains were removed and fixed in ethanol-acetic acid (19:1) for $24 \mathrm{~h}$. Coronal brain slices were cut at 2 and $6 \mathrm{~mm}$ anterior to the interaural line and embedded in paraffin. These slices contained the striatum and dorsal hippocampus, respectively. Sections 5-8 $\mu \mathrm{m}$ thick were then cut from these blocks and stained with hematoxylin and eosin.

Observers, who did not know which experimental treatment the tissue source received, analyzed sections. The cerebral cortex and striatum were microscopically evaluated in anterior sections. CA1, CA3 and the dentate gyrus of the hippocampus, and the thalamus were evaluated in posterior sections. Each region was scored for the degree of severity of brain injury, according to our method previously described (17): 0, no damage; $1, \leq 25 \%$ of the relevant area in a single section damaged; $2,>25 \%$ but $<50 \%$; and 3 , $>50 \%$.

Statistics. All data are expressed as means \pm SEM. The brain injury scores for each brain region were compared between the experimental and control groups using the Mann-Whitney rank sum test. The detection level for serum corticosterone level was $20 \mathrm{ng} / \mathrm{mL}$. When serum corticosterone could not be detected, we used the value of $20 \mathrm{ng} / \mathrm{mL}$ in the statistical analysis. Two-way ANOVA was used to analyze the changes in serum corticosterone levels, followed by Mann-Whitney $U$ test for posthoc analysis. $p<0.05$ was considered statistically significant.

\section{RESULTS}

Zero to four rats died in each group within $24 \mathrm{~h}$ after HI stress (Table 1). There were no differences in mortality rates between study groups. There were no differences between each of the pairs of the groups in body weight seven days after HI stress (data not shown).
LPS4h group. LPS increased brain injury scores in all parts of cerebrum when it was administered $4 \mathrm{~h}$ before HI stress, compared with the saline controls (Fig. 1): cortex, $2.4 \pm 0.3$ versus $0.8 \pm 0.3(p<0.01$, mean \pm SEM of the LPS-treated versus saline-treated groups, respectively); hippocampal CA1, $2.2 \pm 0.3$ versus $0.5 \pm 0.3(p<0.01)$; hippocampal CA3, 2.5 \pm 0.3 versus $0.9 \pm 0.3(p<0.01)$, hippocampal dentate gyrus, $1.3 \pm 0.3$ versus $0.7 \pm 0.7(p<0.01)$, thalamus, $1.0 \pm$ 0.2 versus $0.2 \pm 0.2(p<0.01)$, and striatum, $2.4 \pm 0.3$ versus $0.6 \pm 0.3(p<0.01)$.

LPS24h group. LPS reduced injury scores in all parts of cerebrum, except for the dentate gyrus of the hippocampus, when it was administered $24 \mathrm{~h}$ before $\mathrm{HI}$ stress, compared with the saline controls (Fig. 2): cortex, $0.6 \pm 0.3$ versus $2.1 \pm 0.4$ ( $p$ $<0.01$, mean \pm SEM for the LPS-treated versus saline-treated groups, respectively); hippocampal CA1, $0.7 \pm 0.3$ versus $2.1 \pm$ 0.4 ( $p<0.01$ ); hippocampal CA3, $1.0 \pm 0.4$ versus $2.1 \pm 0.4$ ( $p$ $<0.05$ ), hippocampal dentate gyrus, $0.3 \pm 0.3$ versus $1.2 \pm 0.4$, thalamus, $0.3 \pm 0.2$ versus $1.0 \pm 0.3(p<0.05)$, and striatum, $0.5 \pm 0.3$ versus $2.1 \pm 0.4(p<0.01)$.

LPS24h + LPS4h group. Double administration of LPS at both 24 and $4 \mathrm{~h}$ before HI stress significantly decreased injury

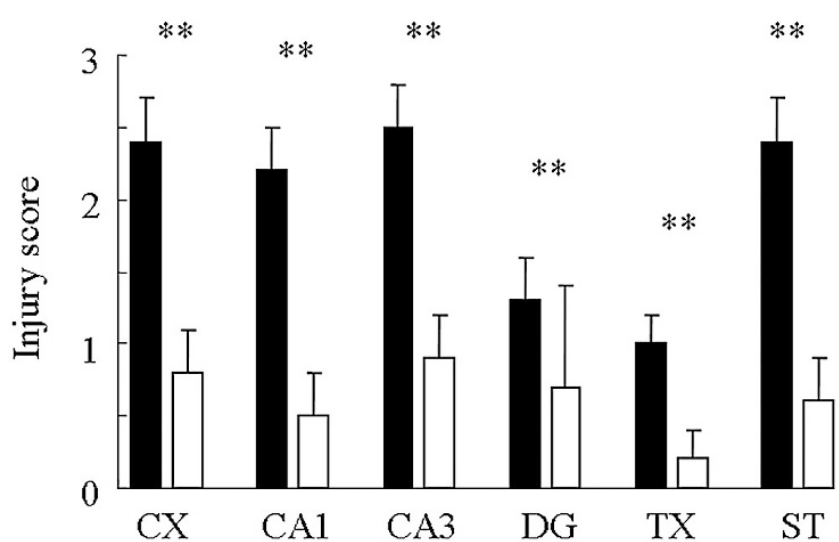

Figure 1. Brain injury scores for 14-d-old Wistar rats that received $1 \mathrm{mg} / \mathrm{kg}$ of LPS (LPS4h: solid bars, $n=14$ ) or saline (Saline4h: open bars, $n=14$ ) $4 \mathrm{~h}$ before HI stress at $7 \mathrm{~d}$ after birth. The LPS4h group showed significantly higher scores in each brain region than the Saline4h group. $C X$, frontal cortex; $C A 1$, hippocampal CA1; $C A 3$, hippocampal CA3; $D G$, hippocampal dentate gyrus; $T X$, thalamus; $S T$, striatum. ${ }^{*} p<<0.01,{ }^{*} p<0.05$. 


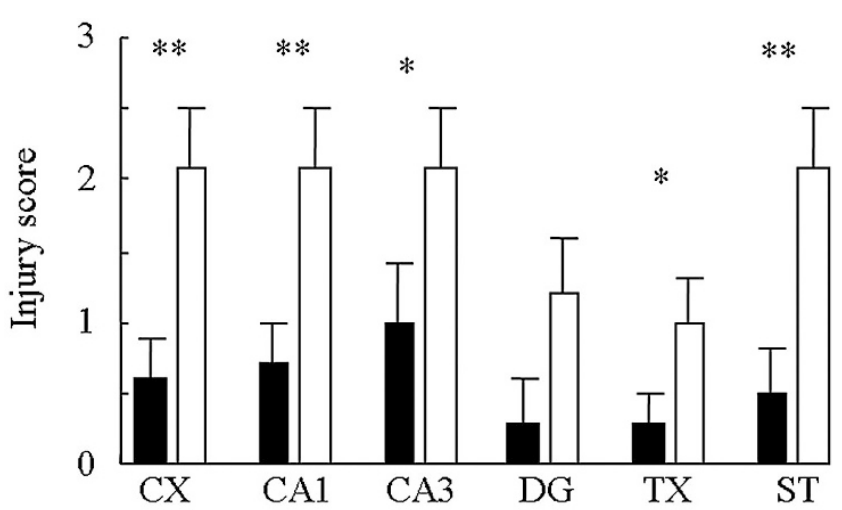

Figure 2. Brain injury scores for the 14-d-old Wistar rats that received 1 $\mathrm{mg} / \mathrm{kg}$ of lipopolysaccharide (LPS24h: solid bars, $n=13$ ) or saline (Saline24h: open bars, $n=10$ ) $24 \mathrm{~h}$ before HI stress at $7 \mathrm{~d}$ after birth. The LPS4h group showed significantly lower scores than the Saline4h group. $C X$, frontal cortex; $C A 1$, hippocampal CA1; $C A 3$, hippocampal CA3; $D G$, hippocampal dentate gyrus; $T X$, thalamus; $S T$, striatum. ${ }^{* *} p<0.01,{ }^{*} p<0.05$.

scores in all the parts of the cerebrum, except for the hippocampal dentate gyrus, compared with the saline controls (Fig. 3): cortex, $0.3 \pm 0.3$ versus $2.0 \pm 0.4(p<0.01$; mean \pm SEM, LPS-treated versus saline-treated groups, respectively); hippocampal CA1, $0.4 \pm 0.3$ versus $1.7 \pm 0.4(p<$ $0.01)$; hippocampal CA3, $0.5 \pm 0.3$ versus $2.1 \pm 0.4(p<$ $0.05)$, hippocampal dentate gyrus, $0.3 \pm 0.3$ versus $0.6 \pm 0.3$, thalamus, $0.3 \pm 0.3$ versus $1.1 \pm 0.3(p<0.05)$, and striatum, $0.3 \pm 0.3$ versus $2.0 \pm 0.4(p<0.01)$.

Effect of RU486 on HI-induced brain damage. There were no significant differences in the injury scores for all the parts of the cerebrum between the groups received RU486 and DMSO before HI (Fig. 4): cortex, $1.8 \pm 0.4$ versus $1.8 \pm 0.4$ (mean \pm SEM, RU486-treated versus vehicle-treated groups, respectively); hippocampal CA1, $1.9 \pm 0.4$ versus $1.9 \pm 0.4$; hippocampal CA3, $2.2 \pm 0.4$ versus $2.0 \pm 0.4$, hippocampal dentate gyrus, $0.7 \pm 0.3$ versus $1.1 \pm 0.3$, thalamus, $0.8 \pm 0.3$ versus $1.2 \pm 0.3$, and striatum, $1.6 \pm 0.4$ versus $1.8 \pm 0.4$.

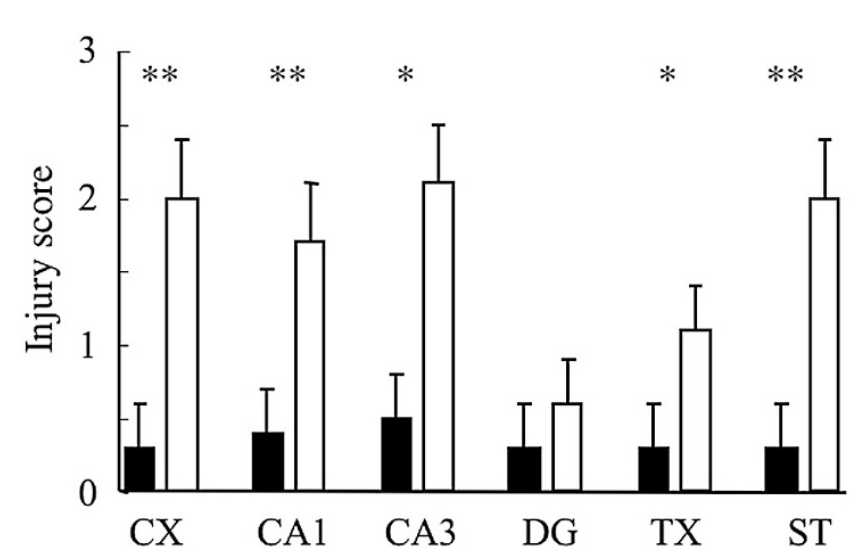

Figure 3. Brain injury scores for the 14-d-old Wistar rats that received 1 $\mathrm{mg} / \mathrm{kg}$ of lipopolysaccharide (LPS24h+LPS4h: solid bars, $n=12$ ) or saline (Saline24h+Saline4h: open bars, $n=13$ ) 24 and 4 hours before HI stress at $7 \mathrm{~d}$ after birth. The LPS24h+LPS4h group showed significantly lower scores than the Saline $24 \mathrm{~h}+$ Saline $4 \mathrm{~h}$ group. $C X$, frontal cortex; $C A 1$, hippocampal CA1; $C A 3$, hippocampal CA3; $D G$, hippocampal dentate gyrus; $T X$, thalamus; $S T$, striatum. ${ }^{* *} p<0.01, * p<0.05$.

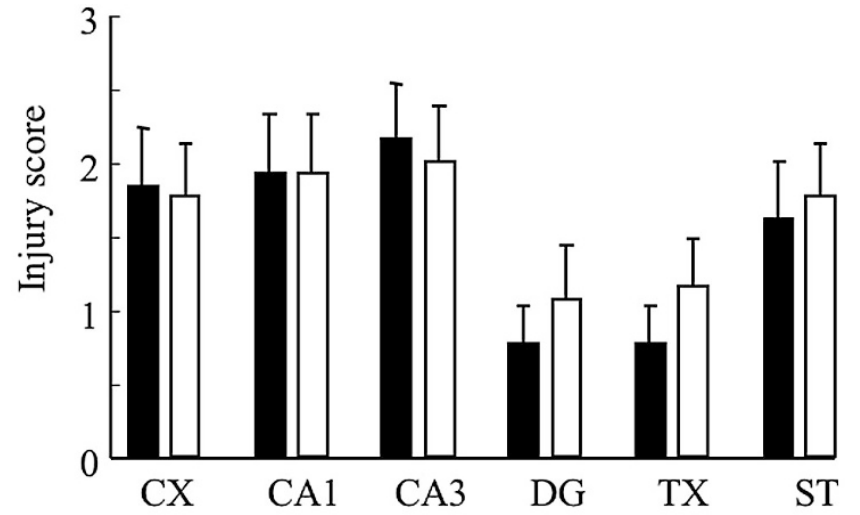

Figure 4. Brain injury scores for the 14-d-old Wistar rats that received $60 \mu \mathrm{g} / \mathrm{kg}$ of RU486, glucocorticoid receptor blocker (Saline24h-RU486: solid bars, $n=$ 13) or DMSO (Saline24h-vehicle: open bars, $n=13$ ) $24 \mathrm{~h}$ before HI stress at $7 \mathrm{~d}$ after birth. The brain injury scores were equivalent in both groups. $C X$, frontal cortex; $C A 1$, hippocampal CA1; $C A 3$, hippocampal CA3; $D G$, hippocampal dentate gyrus; TX, thalamus; $S T$, striatum. ${ }^{* *} p<0.01,{ }^{*} p<0.05$.

Effect of RU486 on brain damage induced by combination of LPS and HI. The RU486-treated group tended to have higher injury scores in most regions compared with the vehicle-treated group, with statistical significance only in the hippocampal CA3 region (Fig. 5): cortex, $1.7 \pm 0.4$ versus 0.8 \pm 0.4 (mean \pm SEM, RU486-treated versus vehicle-treated groups, respectively); hippocampal CA1, $1.8 \pm 0.4$ versus 0.8 \pm 0.4 ; hippocampal CA3, $2.0 \pm 0.4$ versus $0.8 \pm 0.4(p<$ 0.05 ), hippocampal dentate gyrus, $1.0 \pm 0.4$ versus $0.3 \pm 0.3$, thalamus, $1.1 \pm 0.3$ versus $0.3 \pm 0.3$, and striatum, $1.8 \pm 0.4$ versus $0.4 \pm 0.4$.

Serum corticosterone level after LPS administration at PND 6. The serum levels of corticosterone in 6-d-old rats were below the detection limit of the assay $(20 \mathrm{ng} / \mathrm{mL})$ when sampled before injection of LPS or normal saline. The corticosterone level had significantly increased $6 \mathrm{~h}$ after the administration of LPS at PND 6, to $119.6 \pm 10.9 \mathrm{ng} / \mathrm{mL}(p<$ 0.01). The corticosterone level decreased to $57.9 \pm 8.6 \mathrm{ng} / \mathrm{mL}$

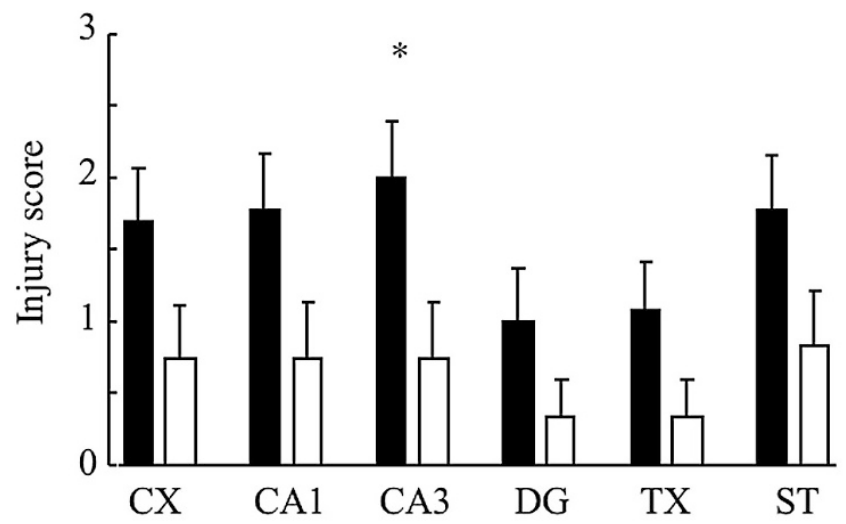

Figure 5. Brain injury scores for the 14-d-old Wistar rats that received 60 $\mu \mathrm{g} / \mathrm{kg}$ of RU486, glucocorticoid receptor blocker (LPS24h-RU486: solid bars, $n=12$ ) or DMSO (LSP24h-vehicle: open bars, $n=14$ ) $24 \mathrm{~h}$ before HI stress at $7 \mathrm{~d}$ after birth. Both groups received $1 \mathrm{mg} / \mathrm{kg}$ of lipopolysaccharide $24 \mathrm{~h}$ before HI. LPS24h-RU486 group showed significantly higher scores in hippocampal CA3 than the Saline24h-vehicle group. $C X$, frontal cortex; $C A 1$, hippocampal CA1; $C A 3$, hippocampal CA3; $D G$, hippocampal dentate gyrus; $T X$, thalamus; $S T$, striatum. ${ }^{*} p<0.01, * p<0.05$. 


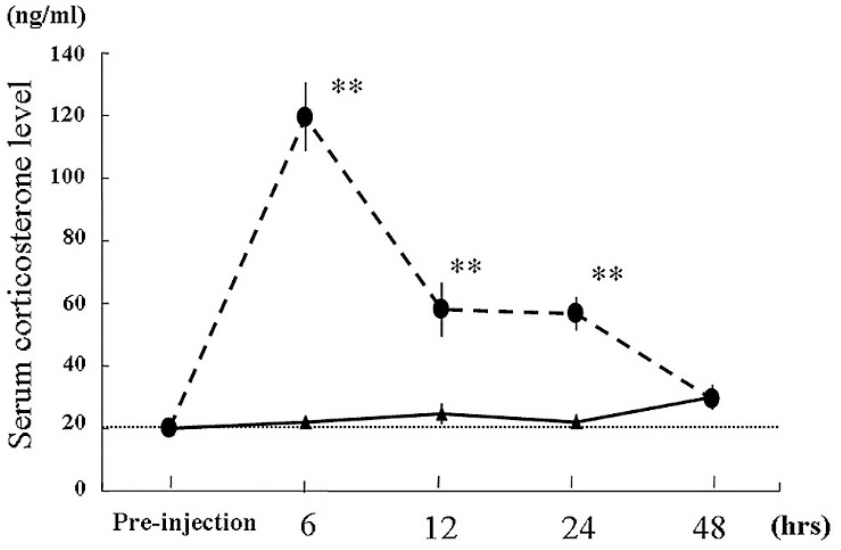

Figure 6. The serum corticosterone levels before and after administration of LPS $(1 \mathrm{mg} / \mathrm{kg})(\boldsymbol{\bullet}, n=28)$ or saline $(\boldsymbol{\Lambda}, n=27)$ at PND 6. $* * p<0.01$, compared with saline-injected group. The dotted line was the detection limit (20 ng/mL). Animal numbers at each point were 5-7.

and $56.8 \pm 5.5$ at $12 \mathrm{~h}$ and $24 \mathrm{~h}$, respectively. These values were higher than those in saline-injected control $(24.8 \pm 3.2$ $\mathrm{ng} / \mathrm{mL}$ and $22.3 \pm 2.3$ at $12 \mathrm{~h}$ and $24 \mathrm{~h}$, respectively; $p<$ $0.01)$. The corticotropin levels did not differ between the LPSand vehicle-treated groups $(29.1 \pm 3.3 \mathrm{ng} / \mathrm{mL}$ versus $30.0 \pm$ $4.3 \mathrm{ng} / \mathrm{mL}) 48 \mathrm{~h}$ after the LPS administration.

\section{DISCUSSION}

LPS administered $4 \mathrm{~h}$ before HI sensitized the brain and increased HI-induced brain injury, whereas LPS induced tolerance against $\mathrm{HI}$ injury if it was injected $24 \mathrm{~h}$ before $\mathrm{HI}$. These findings were consistent with the results of the previous studies $(5,18)$. It is intriguing that the double injections of LPS at 24 and $4 \mathrm{~h}$ before $\mathrm{HI}$ resulted in significant reductions in HI-induced brain injury. These results indicate that LPS stimulates the production of both neuroprotective and neurodegenerative factors. However, the neuroprotection offered by LPS given $24 \mathrm{~h}$ before the insult was strong enough to counteract the aggravating effect of LPS given shortly before the HI.

We have reported recently that the combined treatment of LPS with HI, with a 4-h interval between the two stresses, produces characteristically long-lasting memory and learning impairments, and more extensive cerebral injury than is seen in rats with either LPS or HI alone (13). Furthermore, dexamethasone treatment given $4 \mathrm{~h}$ before HI prevents the histologic and behavioral impairments (11). These result are quite remarkable, with the protective effect of dexamethasone almost total, in agreement with studies showing that dexamethasone provides complete protection if given before HI $(19,20)$. Because glucocorticosteroids are present endogenously and up-regulated by LPS administration in neonatal rats (21), our hypothesis is that LPS-induced glucocorticoids are critical to the preconditioning process against subsequent HI stress.

Our second series of experiments using a glucocorticoid receptor blocker supports this hypothesis. RU486 offset the LPS-induced tolerance and aggravated the HI-induced brain injury imposed $24 \mathrm{~h}$ later, compared with the controls.

Muramatsu et al. (22) showed that dexamethasone ameliorates neuronal necrosis in PND-7 rats, but not in PND-21 rats.
They speculated that dexamethasone may have strengthened the blood-brain barrier, resulting in a reduction in macromolecular extravasation. We studied hyperthermic preconditioning with brain temperatures maintained between 41.5 and $42.0^{\circ} \mathrm{C}$ for $15 \mathrm{~min}$. This significantly reduced macromolecular extravasation, indicating that disruption of the blood-brain barrier was prevented (8). Serum cortisol, measured $24 \mathrm{~h}$ after the $\mathrm{HI}$ insult in these experiments, was significantly higher in the preheated group than in the nonheated group, suggesting that hyperthermia-induced adrenal corticosteroids prevented disruption of the blood-brain barrier.

Several theories have been proposed to explain HI tolerance, including a hypoxia-inducible factor (23), nitric oxide (24), a downstream messenger in tumor necrosis factor alpha signaling, ceramide (25) or partial caspase 3 activation (26). In our previous study, we observed hyperthermia-induced HI tolerance at 6,12 , and $24 \mathrm{~h}$ after hyperthermic preconditioning, but not at 48 or $72 \mathrm{~h}$. Heat shock protein 72 expressed in the vascular endothelial cells, rather than in the glial or neuronal cells, was most strongly associated with HI tolerance. Gidday et al. (24) concluded from their neonatal rat experiments that nitric oxide produced by the endothelial nitric oxide synthase (NOS) isoform is more important than neuronal NOS isoform for acquiring HI tolerance. The underlying mechanisms for $\mathrm{HI}$ tolerance in immature animals therefore appear to be different from those in mature animals, with the functional integrity of the vascular endothelial cells in the cerebrum the more important factor in the immature brain. Muramatsu et al. (22) studied the age-dependent effects of HI on the disruption of the blood-brain barrier in PND-7 and -21 rats. In their study, $1.5 \mathrm{~h}$ of $\mathrm{HI}$ at $37^{\circ} \mathrm{C}$ produced macromolecular extravasation in PND-7 rats, but not in PND-21 rats, although neuronal necrosis was equivalent at these two different ages. Our present data suggest that corticosteroids play an important role in $\mathrm{HI}$ tolerance.

It is important to note that RU486 did not aggravate the HI-induced brain injury produced $24 \mathrm{~h}$ later in the salineinjected animals, in contrast to the effects in the LPS-injected animals. This indicates that endogenously produced glucocorticoids do not appear to be involved in the regulation of cerebral vulnerability to HI. The results are consistent with those published by Tuor et al. (16), and the explanation may be the very low levels of serum corticosterone we found. These levels are due to adrenal quiescence during the first 2 wk of postnatal life (27).

The significant up-regulation of serum corticosterone levels after LPS administration at PND 6 was consistent with a previous report (21). It is important to determine whether such transient increases in corticosterone are exclusively a response to acquiring $\mathrm{HI}$ tolerance. This is under investigation using exogenous corticosterone injections in rats. Although the adrenal gland shows the lowest response to stress at PND 7, endotoxin effectively stimulated adrenal secretion of corticosterone. However, the response is different in the immature brain (21). In the neonatal rat, endotoxin can induce adrenocorticotropic hormone and corticosterone secretion, but it decreases CRH-gene expression in the paraventricular nucleus. This effect is the opposite of that seen in the adult rat. 
Corticosteroids have a two-sided effect on the developing brain (22). Adverse effects include retarded fetal brain growth (23), delay in the myelination (24), and decreased numbers of neuron and degeneration of synaptic terminals (25) in animal studies. Human studies also reported that corticosteroids in perinatal period were associated with reduction of head circumference (26) and cerebral palsy (27). Whether LPSinduced endogenous corticosterone observed in the present study is associated with degenerative effects on the developing brain should be elucidated in the future.

In conclusion, our results indicate that glucocorticoids are critically involved in LPS-induced cerebral tolerance in immature rats. LPS-induced endogenous secretion of corticosterone and the inhibition of glucocorticoid receptors shifted the LPS response from preconditioning to sensitization. In clinical situations involving chorioamnionitis, endogenous glucocorticoids may be critical to improving fetal and neonatal neurologic outcomes.

\section{REFERENCES}

1. Dammann O, Leviton A 1997 Maternal intrauterine infection, cytokines, and brain damage in the preterm newborn. Pediatr Res 42:1-8

2. Saliba E, Marret S 2001 Cerebral white matter damage in the preterm infant: pathophysiology and risk factors. Semin Neonatol 6:121-133

3. Lahra MM, Jeffery HE 2004 A fetal response to chorioamnionitis is associated with early survival after preterm birth. Am J Obstet Gynecol 190:147-15

4. Shimoya K, Taniguchi T, Matsuzaki N, Moriyama A, Murata Y, Kitajima H, Fujimura M, Nakayama M 2000 Chorioamnionitis decreased incidence of respiratory distress syndrome by elevating fetal interleukin-6 serum concentration. Hum Reprod 15:2234-2240

5. Eklind S, Mallard C, Arvidsson P, Hagberg H 2005 Lipopolysaccharide induces both a primary and a secondary phase of sensitization in the developing rat brain. Pediatr Res 58:112-116

6. Dawson DA, Furuya K, Gotoh J, Nakao Y, Hallenbeck JM 1999 Cerebrovascular hemodynamics and ischemic tolerance: lipopolysaccharide-induced resistance to focal cerebral ischemia is not due to changes in severity of the initial ischemic insult, but is associated with preservation of microvascular perfusion. J Cereb Blood Flow Metab 19:616-623

7. Ota A, Ikeda T, Abe K, Sameshima H, Xia XY, Xia YX, Ikenoue T 1998 Hypoxic-ischemic tolerance phenomenon observed in neonatal rat brain. Am J Obstet Gynecol 179:1075-1078

8. Ikeda T, Xia XY, Xia YX, Ikenoue T 1999 Hyperthermic preconditioning prevents blood-brain barrier disruption produced by hypoxia-ischemia in newborn rat. Brain Res Dev Brain Res 117:53-58

9. Ikeda T, Ikenoue T, Xia XY, Xia YX 2000 Important role of 72-kd heat shock protein expression in the endothelial cell in acquisition of hypoxic-ischemic tolerance in the immature rat. Am J Obstet Gynecol 182:380-386

10. Nadeau S, Rivest S 2003 Glucocorticoids play a fundamental role in protecting the brain during innate immune response. J Neurosci 23:5536-5544

11. Ikeda T, Mishima K, Aoo N, Liu AX, Egashira N, Iwasaki K, Fujiwara M, Ikenoue T 2005 Dexamethasone prevents long-lasting learning impairment following a combination of lipopolysaccharide and hypoxia-ischemia in neonatal rats. Am J Obstet Gynecol 192:719-726
12. Levine S 1960 Anoxic-ischemic encephalopathy in rats. Am J Pathol 36:1-17

13. Ikeda T, Mishima K, Aoo N, Egashira N, Iwasaki K, Fujiwara M, Ikenoue T 2004 Combination treatment of neonatal rats with hypoxia-ischemia and endotoxin induces long-lasting memory and learning impairment that is associated with extended cerebral damage. Am J Obstet Gynecol 191:2132-2141

14. Mortola JP, Dotta A 1992 Effects of hypoxia and ambient temperature on gaseous metabolism of newborn rats. Am J Physiol 263:R267-R272

15. Okimoto DK, Blaus A, Schmidt M, Gordon MK, Dent GW, Levine S 2002 Differential expression of c-fos and tyrosine hydroxylase mRNA in the adrenal gland of the infant rat: evidence for an adrenal hyporesponsive period. Endocrinology 143:1717-1725

16. Tuor UI, Del Bigio MR 1996 Protection against hypoxic-ischemic damage with corticosterone and dexamethasone: inhibition of effect by a glucocorticoid antagonist RU38486. Brain Res 743:258-262

17. Ota A, Ikeda T, Ikenoue T, Toshimori K 1997 Sequence of neuronal responses assessed by immunohistochemistry in the newborn rat brain after hypoxia-ischemia. Am J Obstet Gynecol 177:519-526

18. Eklind S, Mallard C, Leverin AL, Gilland E, Blomgren K, Mattsby-Baltzer I, Hagberg H 2001 Bacterial endotoxin sensitizes the immature brain to hypoxicischaemic injury. Eur J Neurosci 13:1101-1106

19. Ikeda T, Mishima K, Yoshikawa T, Iwasaki K, Fujiwara M, Xia YX, Ikenoue T 2002 Dexamethasone prevents long-lasting learning impairment following neonatal hypoxic-ischemic brain insult in rats. Behav Brain Res 136:161-170

20. Barks JD, Post M, Tuor UI 1991 Dexamethasone prevents hypoxic-ischemic brain damage in the neonatal rat. Pediatr Res 29:558-563

21. Dent GW, Smith MA, Levine S 1999 The ontogeny of the neuroendocrine response to endotoxin. Brain Res Dev Brain Res 117:21-29

22. Muramatsu K, Fukuda A, Togari H, Wada Y, Nishino H 1997 Vulnerability to cerebral hypoxic-ischemic insult in neonatal but not in adult rats is in parallel with disruption of the blood-brain barrier. Stroke 28:2281-2289

23. Bergeron M, Gidday JM, Yu AY, Semenza GL, Ferriero DM, Sharp FR 2000 Role of hypoxia-inducible factor-1 in hypoxia-induced ischemic tolerance in neonatal rat brain. Ann Neurol 48:285-296

24. Gidday JM, Shah AR, Maceren RG, Wang Q, Pelligrino DA, Holtzman DM, Park TS 1999 Nitric oxide mediates cerebral ischemic tolerance in a neonatal rat model of hypoxic preconditioning. J Cereb Blood Flow Metab 19:331-340

25. Zimmermann C, Ginis I, Furuya K, Klimanis D, Ruetzler C, Spatz M, Hallenbeck JM 2001 Lipopolysaccharide-induced ischemic tolerance is associated with increased levels of ceramide in brain and in plasma. Brain Res 895:59-65

26. McLaughlin B, Hartnett KA, Erhardt JA, Legos JJ, White RF, Barone FC, Aizenman E 2003 Caspase 3 activation is essential for neuroprotection in preconditioning. Proc Natl Acad Sci U S A 100:715-720

27. Vallette G, Delorme J, Benassayag C, Savu L, Nunez EA, Meijs-Roelofs HM, Kramer P 1982 Developmental patterns of levels of corticosterone and of corticosterone binding in the serum of female rats: effects of ovariectomy and adrenalectomy. Acta Endocrinol (Copenh) 101:442-451

28. Goldenberg RL, Wright LL 2001 Repeated courses of antenatal corticosteroids. Obstet Gynecol 97:316-317

29. Huang WL, Beazley LD, Quinlivan JA, Evans SF, Newnham JP, Dunlop SA 1999 Effect of corticosteroids on brain growth in fetal sheep. Obstet Gynecol 94:213-218

30. Dunlop SA, Archer MA, Quinlivan JA, Beazley LD, Newnham JP 1997 Repeated prenatal corticosteroids delay myelination in the ovine central nervous system. J Matern Fetal Med 6:309-313

31. Uno H, Lohmiller L, Thieme C, Kemnitz JW, Engle MJ, Roecker EB, Farrell PM 1990 Brain damage induced by prenatal exposure to dexamethasone in fetal rhesus macaques. I. Hippocampus. Brain Res Dev Brain Res 53:157-167

32. French NP, Hagan R, Evans SF, Godfrey M, Newnham JP 1999 Repeated antenatal corticosteroids: size at birth and subsequent development. Am J Obstet Gynecol 180:114-121

33. Papile LA, Tyson JE, Stoll BJ, Wright LL, Donovan EF, Bauer CR, KrauseSteinrauf H, Verter J, Korones SB, Lemons JA, Fanaroff AA, Stevenson DK 1998 A multicenter trial of two dexamethasone regimens in ventilator-dependent premature infants. N Engl J Med 338:1112-1118 